\title{
The Impact of the Use of Computer Technology and Auditing Software on the Efficiency of External Auditors in Jordan
}

\author{
Mohammed Alsharairi ${ }^{1}$, Atallah Ahmad Alhosban ${ }^{2,}$ * \\ ${ }^{1}$ Financial and Managerial College, Irbid National University, Irbid, Jordan \\ ${ }^{2}$ Financial and Managerial College, Aqaba University of Technology, Aqaba, Jordan
}

Email address:

aalhosban@gmail.com (A. A. Alhosban)

${ }^{*}$ Corresponding author

\section{To cite this article:}

Mohammed Alsharairi, Atallah Ahmad Alhosban. The Impact of the Use of Computer Technology and Auditing Software on the Efficiency of External Auditors in Jordan. International Journal of Business and Economics Research. Vol. 8, No. 4, 2019, pp. 201-210. doi: $10.11648 /$ j.ijber.20190804.15

Received: May 26, 2019; Accepted: June 27, 2019; Published: July 16, 2019

\begin{abstract}
The study aims to achieve the following objectives to identify the impact of the use of electronic work environment tools to increase the efficiency of external auditors, Highlight the importance of using audit programs to increase the efficiency of external auditors. The researcher designed the questionnaire for the current study to identify the effect of using modern technology on the work environment of the external auditors. To analyze the data used by the Statistical Package for Social Sciences (SPSS), the following statistical methods were used: Statistical descriptive methods: represented by arithmetic mean, standard deviation and repetitions in order to obtain the general characteristics of the sample of the study sample. Most results: The computer hardware technology helps the external auditor to test the means of control over the electronic system. The presence of computer technology and tools helps the external auditor to reasonably confirm that the data received for processing purposes is licensed and has been properly translated into computer language. Most recommendation: There should be legislations and laws governing the work of external auditors in the establishments that use the computer, the application of the study to the internal auditors or financial managers and sectors, which helps to integrate the views in the audit process.
\end{abstract}

Keywords: External Auditors, Computers, Audit Program, Commercial Banks

\section{Introduction}

With the growing use of the computer, public shareholding companies have worked on data processing electronically, so that information technology has become part of the company's environment, and that information systems continue to impact on the operations of different companies and their data processing. As the most attractive sectors of technology are public shareholding companies, so this study came to examine the extent to which internal control systems in these companies respond to IT requirements. The electronic work environment has imposed a new reality on the auditing profession in Jordan as a result of the computerization of most Jordanian companies for their accounting programs and computerization of their financial and administrative files, which led to the need to increase the efficiency of the external auditors in Jordan to the requirements of the electronic work environment which requires keeping pace with the electronic work environment through change For modern electronic auditing methods. The availability of audit programs also has an impact on increasing the efficiency of external auditors through the design of a special prang suited to the nature of their work, or designing audit programs generally used by external auditors in Jordan.

\subsection{The Problem of the Study}

This study attempts to answer the following question: "What is the use of computer technology and electronic auditing programs to increase the efficiency of external 
auditors in Jordan?

The elements of the study problem are

1. What is the impact of the use of electronic work environment technology to increase the efficiency of external auditors in Jordan?

2. What is the impact of the use of electronic auditing programs on increasing the efficiency of external auditors in Jordan?

\subsection{Hypotheses of the Study}

Based on the study problem, the following hypotheses can be formulated:

1. Is there no impact on the use of electronic work environment technology to increase the efficiency of external auditors in Jordan?

2. Is there no impact on the use of electronic auditing programs to increase the efficiency of external auditors in Jordan?

\subsection{Importance of Studying}

The profession of auditing is a necessary profession in providing services to many parties such as shareholders, investors, creditors, tax services, trade union societies and other beneficiaries. In order to upgrade the profession, it is important for the audit profession to keep pace with the electronic auditing environment and the mechanisms of preparing the electronic report to improve the auditing profession. The use of the electronic work environment and the use of risks such as the penetration or modification of accounting data, which increases the efficiency of auditing and linking the audit using available information technology tools, which reflects the validity of the auditor's opinion in the computerized accounting data.

\subsection{Objectives of the Study}

The study aims to achieve the following objectives

1. To identify the impact of the use of electronic work environment tools to increase the efficiency of external auditors.

2. Highlight the importance of using audit programs to increase the efficiency of external auditors.

3. linking the theoretical framework to the practical framework through the possibility of determining the degree of compliance with external auditors of the requirements of the electronic work environment.

4. Identifying strengths Weak weaknesses to develop the efficiency of external auditors to perform various audit functions.

5. Outcomes and recommendations to help identify the problems or obstacles to the use of electronic work environment tools in the external audit profession.

\subsection{Previous Studies}

1. Deihani study 2016 "The role of electronic auditing in the development of the performance of the external auditor in the State of Kuwait
The study aimed to identify the role of electronic work environment tools such as computers and peripherals, computer networks, databases, IT planning, training and training of auditors, and information security. The questionnaire consisted of 48 multiple-choice items. The questionnaires were distributed to a sample of the audit offices that perform the electronic auditing process both within the audit office and in the auditing companies. Statistical methods were used, such as: the Kronbach Alpha test to find the degree of internal consistency of the responses of the study sample members, which was $93 \%$, and a sample test was used to test the hypotheses. The most important results of the study that the tools or variables of the electronic work environment have a positive impact in the development of external audit performance. The most important recommendations of the study: the need to hold specialized conferences in electronic auditing and focus on the benefits achieved by electronic auditing of external auditing, and the need to apply the variables of study on the government sector. [1]

2. Ali Ali Al-Ansi, Noor Azizi Bin Ismail \& Abdullah Kaid Al-Swidi (2017) " The Effect of IT knowledge and IT Training on the IT Utilization among External Auditors: Evidence from Yemen

This study aimed to investigate the level of IT utilization and the factors that influence the IT utilization among the audit practitioners in Yemen. The proposed model invest tigates the impact of IT knowledge, IT training and firm category on the IT utilization. The researchers use a survey questionnaire, the data were collected from 197 external auditors representing Big-4 and non-Big-4 firm s operating in Yemen. The Partial Least Squares (PLS) Structural Equations Modeling Approach was employed to analyze the data and test the proposed model. The results showed that IT knowledge and IT training significantly contributed to IT utilization among the external auditors. The originality of this paper comes from the way it contributes towards understanding the joint effect of IT knowledge and training in understanding the IT utilization. In addition, it enhances the current understanding of the moderating effect of the firm category, Big 4 and Non-Big 4, on the relationship between the IT Training and the IT utilization among external auditors. [2]

3. Atallah Ahmad Alhosban, Mohammed Al-Sharairi (2017) "Role of Internal Auditor in Dealing with Computer Networks Technology - Applied Study in Islamic Banks in Jordan"

The aim of the study was to identify Role of internal auditor in dealing with computer networks technology Applied study in Islamic banks in Jordan -. The objectives were to identify the role of the computer networks that are installed for the first time in addition to the role of the auditor in the physical components of computer networks and maintenance. The study community consists of internal auditors in Islamic banks or financial institutions, a total of 101 questionnaires were distributed and 89 questionnaires were retrieved for statistical analysis. A 
single sample test was used to test the hypotheses of the study. The arithmetic mean and the alpha test were used to find the internal consistency rate of the study sample. The most important results of the study: the presence of the impact of computer networks on the internal audit work environment both in the installation of the computer for the first time or provide the physical components of computer networks. The most important recommendations: The need to hold seminars and conferences using technology tools and their effects on the environment of internal auditing or external auditing or accounting environment in general. [3]

The current study differs with previous studies as follows

1. This study focuses on the impact of the use of electronic work environment tools on the nature of the work of external audit and the role of these tools in increasing the efficiency of external auditors

2. This study focuses on the impact of the use of various auditing programs to increase the efficiency of the external audit profession in Jordan

3. This study focuses on the role of the electronic work environment in developing and increasing the efficiency of external auditing in Jordan

\section{The Theoretical Framework of the Study}

The auditor should understand the characteristics of the electronic work environment and take into consideration that it affects the design of the accounting system and the internal control systems in the establishment. This will inevitably affect the comprehensive audit plan and strategy. The electronic audit was accompanied by many risks such as data penetration or modification. Audit standards such as the International Auditing Standards and the American Institute of Certified Public Accountants (ACPA) issue standards and methods for electronic auditing to be an indicative list of external auditors in carrying out audits of the audited institution, The auditor shall maintain professional knowledge and skills at the level required to ensure the provision of high quality professional services to the client based on IT developments in practices, legislation and methods and perform his or her duties diligently and in accordance with the applicable technical and professional standards. The auditor shall also obtain reasonable assurance as to whether The financial statements as a whole are free from material misstatement, whether due to fraud or error, which enables the auditor to issue an opinion as to whether the audited financial statements are in conformity with generally accepted accounting principles and in accordance with the standards for review External approved or is it not in conformity with accounting standards and standards of external auditing. [4]

The computer is now the main means of processing data in various aspects of economic activity in public and private institutions. With the increasing use of computers and thus the information technology and the growing awareness that the data on which the operations of institutions depend and the certainty that the information derived from these data paints the image of the institution and its environment and future. There is increasing concern that there is insufficient control over the work of computers and information technology. Thus, the spread of the use of information technology in the public and private sectors, led to the need to keep up with the internal control system of the requirements of this technology, the auditor also aims to find ways to secure information and maintain certain benefits and the use of auditing Electronic and information and communication systems that help to deliver this accounting information in a timely manner, and to maintain it from the foot which often results in lack of appropriateness, mistrust or lack. [5]

\subsection{General Characteristics of the Electronic Work Environment}

International auditing standards indicate that an electronic work environment exists in an environment where the electronic computer is used as a key tool in recording and migrating its accounting processes so that the accounting cycle is fully computerized, whether the computer is operating from the entity or a third party. [6]

1. Organizational structure: The organization's management shall formulate an organizational structure that clarifies the powers and authorities of the employees in the electronic work environment. The organizational structure includes: Focusing of functions and knowledge so that the powers related to the electronic work environment are specific in specific persons so that the auditor can obtain the data he wants easily and easily. The auditor determines who is responsible for the errors in the computerized audit process. The organizational structure also includes the concentration of programs and data through the availability of authorized transit to enter the company data stored on the computerized program.

2. The nature of the treatments: so that the accounting processes have mechanisms to enter from the accountants or specific employees, because the processes of electronic processing are: the absence of documents Inserts, and the loss of the process of the process (some processes stored on the computer and some processes registered manually), and easy access to Data and software.

3. Design and Procedural Procedures: Electronic data processing procedures differ from manual data procedures. The design and procedures include: device stability (software stability and reliability of computer networks), programmed control procedures (such as passwords), updating of computer files and files Database, and the existence of systems that generate information or reports that assist the auditor in accomplishing the tasks. 


\subsection{Types of Electronic Auditing System}

International data on auditing practice indicate that electronic work audit systems have the following types [4]:

1. Independent personal computer systems: so that the personal computer can be used in the management of financial operations carried out in the establishment and the possibility of extracting financial reports of the auditor and management, and the organizational structure of the institution is the basis in the degree of safety of the use of personal computers in the management of financial data and reduce risk.

2. Direct computer systems: The use of digital screens and a certain number of computers that are linked to the network of licensed access to computerized programs and allows the auditor to obtain the information that helps in the work of the audit report, and enables programmers to enter the systems of direct computers so that programmers from Modification or extension of computerized accounting software.

3. Database systems: The database refers to a data set that is shared and used by several different users for different purposes. When using the databases, the external auditors need special expertise in information technology to make appropriate inquiries and understand the implicit connotations of the obtained responses. The data has two important characteristics: data sharing and data independence for application programs (ie databases are separate from the work of accountants).

\subsection{The Concept of Electronic Auditing}

Prior to the definition of electronic auditing, the concept must be defined from the electronic work environment, which may differ in its concept from the viewpoint of its employees from its supporters or opponents. Therefore, the electronic work environment can be defined as "a toolkit that helps in receiving, processing, retrieving, In the form of text, sound, image or video, using computer, such as computer, printer, CD, networking and many other tools. [7]

The audit objectives remain the same even under EDI. Thus, electronic auditing (under the use of computers) can be defined as "collection and evaluation to determine whether the use of the computer contributes to the protection of the assets of the enterprise, supports the integrity of its data, achieves its objectives effectively, The external auditor under this operating system should focus on the examination and evaluation of the internal control system, on the understanding that this task determines the scope of its audit, which includes the following elements: [8]

1. Examination and review of data entry system for the computer

2. Examine and review the preparation of computer data

3. Review and review the results

With regard to the concept of auditing the electronic work environment, the following definitions can be developed:

1. It is a double-edged sword, the first aspect of which is that it is a tool of the auditor and the internal control system. The second aspect is the rapid development of modern technology and the continuous risk of auditing. [9]

2. It is based on the use of computers and computer networks in order to provide the necessary information for auditing and use as a tool in them. It helps in understanding the purpose of working in automated accounting systems, in addition to understanding the environment in which modern technology operates and the need to keep pace with recent discoveries of ability to deal with it. [9]

3. It deals with the knowledge and skills, the ability to review and evaluate the development, and the operation of the components of the information systems, whether for the internal auditor or the external auditor, and is also interested in the use of computers, communication means, computer networks, data and information and the means of storage and storage by modern means and developed. [10]

So that, The audit of the electronic work environment is based on the use of information technology tools by the auditor to judge the fairness and validity of the financial statements and to verify the validity and reliability of the computerized accounting software used in processing accounting operations.

\subsection{The Impact of the Electronic Work Environment on External Auditing}

The effect of using the electronic work environment on the external auditor is as follows: [11]

1. The external auditors shall carry out special and general auditing programs appropriate to the nature of their work

2. Qualifying the auditor scientifically and academically with training courses to meet the requirements and risks of the electronic work environment

3. Keeping abreast of technological developments in the application of auditing standards related to the electronic work environment

4. Computerization of the audit procedures by the external auditor with the aim of getting a neutral opinion on the fairness of the financial statements

The electronic audit has increased the skills of the external auditor, which required him to understand and absorb the use of IT tools in order to be able to perform the electronic auditing because it has become one of the main auditing tools in the work of external audit. Electronic data auditing is a method that relies on the use of technologies and development in electronic information technology to handle accounting data and to ensure that the data has been entered, processed and reported correctly. This supports the internal audit function in the control and risk management of financial operations.

The impact of the use of electronic work environment tools on the accounting system and auditing.

Accounting aims to provide appropriate information on the 
activity and outcomes of the business and the financial position of the management and stakeholders to make appropriate decisions, as well as recording the operations of the establishment, extracting results, maintaining the assets of the establishment and protecting their rights. However, the use of the computer changes the accounting structure and procedures And the operation of the data, but it did not change its objectives.

Although the computer is unable to influence accounting objectives, its use affects the components of the accounting work and the audit process and their relationship with each other as follows: [8]

1. the impact of the computer on the accounting group

The use of a computer in accounting requires the modification of the format of these documents or the use of a new documentary set that includes the data contained in the original documents in a manner consistent with the electronic accounting software applied in the facility, as well as the coding system used to access data saved through a means of preservation, Magnetic plastic, magnetic disks.

2. the impact of the computer on the accounting book collection

Accounting books are numerous in the accounting method followed by establishments, but when using a computer, magnetic tape and magnetic disks are accounting books.

3. the impact of the use of computers on financial reports

The use of the computer led to the accuracy and speed of access to financial reports, in addition to the ability to display on the visual display, and thus the speed of change information before they are printed or stored.

4. the impact of using the computer on the accounting guide

The use of the computer has helped to develop the method of preparation of the accounting guide, as well as maintain the confidentiality of data or accounts recorded gross or subas well as the accuracy of the classification of accounts.

5. the impact of the computer on the models of books that are commonly used in accounting

The use of the computer led to the multiplicity of automated accounting software in the markets and thus the preparation of various electronic books that correspond to the nature and size of the work of the establishment, which led to the ease of dealing with these books very quickly at different stages of registration or modification or cancellation of data.

From this we conclude that the effects of using the computer in the accounting system and the audit process are as follows:

1. The objectives of accounting have not changed, whether manual or electronic, but the use of computer impact in the degree of achieving the efficiency of these goals.

2. The use of the computer affects the form and nature of the documentary collection in accounting.

3. The use of the computer has led to accuracy in performance and to faster reporting and display better than in the manual system.

4. Computer use is an extension of human work, but the computer does it quickly and efficiently.

\subsection{Definition of External Audit}

\subsubsection{External Auditing Can Be Defined as the Following}

1. defines external audit as a "cognitive accumulation derived from the assessment of evidence to determine the extent to which economic processes comply with accounting systems and standards in place by a qualified and independent person". [12]

2. comprehensive reviews of the other books and accounting records of the Labor Authority, by external staff members not affiliated with this body, to verify that the accounting records are accurate, complete and comprehensive, and may perform external audit from In order to confirm the results of the internal audit, first to verify that accounting practices are accurate and legal. [13]

So that. It is possible through the above definitions to say that the external audit is to have a neutral and independent person from the entity review the books and records of a particular establishment and to issue a technical report on the opinion of the auditor on the validity and fairness of the financial statements.

\subsubsection{External Audit Objectives}

The external auditors' approach to external auditing in terms of the objectives assigned to it by an activity or means of detecting fraud, fraud and counterfeiting in the records has evolved to the auditor's critical audit of the audited entity's books and records in order to issue an impartial technical opinion in his report to the competent authorities or shareholders The objectives of the external audit are as follows: [11]

1. Existence and verification: ensuring that the different assets already exist in the audited budget, and that the transactions in the financial statements are actually performed during the period under review.

2. Inclusiveness: By verifying that everything that happened and occurred during the fiscal year the subject of the examination was recorded and presented in the financial statements.

3. Valuation: the validation of the valuation and the fact that the cost of provisions is allocated in accordance with generally accepted accounting principles.

4. Ownership and debt: through verification of ownership and that the assets shown in the budget are owned by the company and have no rights to others.

5. Disclosure: Give an objective opinion about the regulations and procedures concerning the protection of the company's properties, the safety and classification of the various accounts of the company and disclosure of the necessary information.

\subsection{When Auditing Computerized Audit Programs, the Auditor Can: [14]}

1. Use audit programs to ensure compliance with regulations and instructions so that the use of 
accounting software is available to all parties, whether employees or customers with the prior authorization of each party related to the computerized accounting programs

2. To improve the efficiency of the audit process of the external auditor through the auditors to identify the weaknesses of the accounting programs and to report to the management on the weaknesses and demand from the software provider to modify the required data

3. Preparation of security measures required for the sensitive data of the company through the use of powers and passwords and various controls

\subsection{The Most Important Programs Used in Computer Auditing Programs [14]}

\subsubsection{Special Audit Programs}

As a result of the development of the processing system it became necessary for the auditor to follow and analyze the information stored on the image of the computer language. Among the tests of the auditor as a solution to this problem is that the designers of the client program or other employees of the computer processing system write special programs to analyze computer files, Is specifically designed to perform certain special auditing tasks.

\subsubsection{General Audit Programs}

These are programs that are designed so that the auditor can use them to audit different types of electronic processing systems regardless of the type of organization or industry. Such programs are prepared by many accounting firms, software and computer suppliers.

Any effective control system must meet the following conditions: [13]

1. Harmonization between the nature of the internal welfare system with the nature of activities that are monitored, and this depends on the size and diversity and the complexity of the products of the establishment or services provided to customers.

2. The system provides indicators to detect deviations before they occur or moment of occurrence so that the company can manage to correct the course of deviations and mitigate the negative risks as much as possible.

3. There is flexibility in the design and implementation of internal control system so that the system can be changed according to developments in the environment of the establishment or changes that may affect the activities.

4. Ensure the integrity of the performance of the control functions as planned and ensure that the expected costs of the internal control system are maintained from the application of the balance of costs with benefits in the event of deviations from the implementation of any plan.

\subsection{Evaluate the Effectiveness of the Internal Control System}

The process of evaluating the effective internal control system is as follows: [13]

1. Provide data and facts on the nature of the reulatory system, which is consistent with the strategy of the establishment and ensure the adequacy of the data with the organization's organizational structure

2. Ensure the correct operation of the facts provided to ensure the effectiveness of data and facts used in the design of the internal control system

3. Ensure proper implementation of internal control procedures with predefined standards through the use of document review and verification of balances

4. Overall evaluation of the system through regular interconnection between previous elements and comparison of actual results with expected results.

\section{Statistical Analysis}

\subsection{Sources of Data Collection}

To achieve the objectives of the study, the researcher sought to use two basic sources of data collection:

1. Secondary sources: The researcher reviewed the library resources and reviewed the previous literature in order to identify the foundations and sound scientific methods in writing the studies, clarify the concepts related to the study and explain the variables, their causes and impact, and to develop the hypotheses of the study, Secondary sources include:

a Accounting and auditing books, accounting information systems, specialized Arabic and foreign articles, and published studies that study the subject of the study.

b Master's thesis and doctoral dissertations that study the subject of the study.

c Information available on the Internet and websites.

2. Primary sources: The study is classified as a field study to collect primary data. To achieve this, the primary data collection was used through questionnaire as a main tool for the study, and preparation of its paragraphs based on the relevant theoretical framework and previous studies, including a number of paragraphs reflecting the objectives and questions of the study, To be answered by the respondents

\subsection{Study Tool}

1. The researcher designed the questionnaire for the current study to identify the effect of using modern technology on the work environment of the external auditors. This tool was designed to cover the hypotheses of the study and the use of evaluative expressions to determine the answers of the sample of the study after an extensive reading of the studies on measuring the study variables. Two sections were represented as follows:

2. Section I: This section was designed to collect personal data about the sample members of the study, including the scientific qualification, years of experience, job 
title, and scientific specialization.

3. The second section is devoted to the terms that cover the independent and dependent variables of the study, and it consists of (14) paragraphs.

4. Thesis (Master and $\mathrm{PhD}$ ).

\subsection{Statistical Processing}

To analyze the data used by the Statistical Package for Social Sciences (SPSS), the following statistical methods were used:

1. Statistical descriptive methods: represented by arithmetic mean, standard deviation and repetitions in order to obtain the general characteristics of the sample of the study sample

2. Stability test (Kronbach Alpha): which measures the degree of internal consistency in the responses of the sample members of the study

3. Test the normal distribution of the data: using the onesample Kolmogorov-Smirnov Test, in order to determine the degree of follow the study tool for natural distribution

\subsection{Reliability}

The Kronbach Alpha test was used to determine the degree of internal consistency of the responses of the study sample members. The value of the Cronbach alpha factor was $76 \%$ for the study in general, which is higher than the minimum threshold of $70 \%$ (Sekaran, 2013). There is a degree of internal consistency acceptable and good, which leads to the stability and credibility in the results and recommendations of the study, and the value of Kronbach Alpha for the first hypothesis $72 \%$, and the second hypothesis $79 \%$, and this also indicates that the degree of internal consistency at the level of study variables are good for the dissemination of the findings and recommendations.

\subsection{Society and Sample of the Study}

The study community consists of external auditors in the audit offices in Jordan. The number of external audit offices in Jordan reached 69 licensed audit offices. The number of external auditors practicing the profession based on telephone communications in these offices was 276 external auditors. The sample of the study consisted of audit offices The number of auditors was 45 audit offices authorized to perform the audit. The number of external audit auditors was 181 external auditors. Random sample method was used to distribute the questionnaires to the audit offices. 130 questionnaires were distributed M Retrieved 105 questionnaires.

\subsection{Statistical Results}

\subsubsection{Characteristics of Study Sample Individuals}

Table 1. Characteristics of the study sample.

\begin{tabular}{llll}
\hline Variable & Title & Frequencies & Percentage \\
\hline \multirow{5}{*}{ Level } & Accounting & 76 & $72 \%$ \\
& Finance & 15 & $14 \%$ \\
& Management & 8 & $7.5 \%$ \\
& Other & 6 & $6.5 \%$ \\
& sum & 105 & $\% 100$ \\
& College & 9 & $8.5 \%$ \\
& Bachelor's & 69 & $67.5 \%$ \\
Exalification & postgraduates & 27 & $25 \%$ \\
& College & 9 & $8.5 \%$ \\
years & sum & 105 & $\% 100$ \\
& Less than 6 years & 42 & $40 \%$ \\
& 6-less than 12 years & 39 & $37 \%$ \\
& 12 years and more & 24 & $23 \%$ \\
\hline
\end{tabular}

It is noted from the above table that the characteristics of the individuals in the study sample include the following

1. The vast majority of the external auditors - the members of the study sample - have a specialization in accounting, and this may be normal since the sample of the study are the external auditors in the audit offices, which has a positive reflection on the validity of the study tool.

2. The vast majority of the sample members of the study have a scientific qualification at the level of bachelor's degree, which means that the study tool distributed to people with a suitable scientific qualification, also notes the existence of a good proportion of postgraduate studies and this has a positive impact on the study of the paragraphs of the study tool Gives a positive reflection on the stability of the results of the study.

3. The ratios of categories of expertise are somewhat similar with a more increase of the category of experience less than 6 years.

\subsubsection{Analysis of the Hypotheses of the Study}

Discuss the hypotheses of the study with the statistical results as follows: The first hypothesis that "there is no impact to the use of electronic work environment technology to increase the efficiency of external auditors in Jordan".

Table 2. The views of the study sample by the variable of the accounting control.

\begin{tabular}{|c|c|c|c|c|}
\hline No & Paragraph & Weighted average & Standard deviation & Rank \\
\hline 1 & The operating system in the bank works well, which helps to avoid penetration & 3.86 & 0.88 & 5 \\
\hline 2 & $\begin{array}{l}\text { The presence of internal and external coordination between computer units and } \\
\text { audit units contributed to the development of external audit performance }\end{array}$ & 4.00 & 0.85 & 3 \\
\hline 3 & $\begin{array}{l}\text { There are specific tasks of reference for external auditors in the use of computer } \\
\text { technology tools, which allows them to develop their performance }\end{array}$ & 3.56 & 0.74 & 7 \\
\hline 4 & $\begin{array}{l}\text { The external auditor shall review the integrity of the executive procedures in } \\
\text { entering and leaving the accounting program in order to ensure the integrity of the }\end{array}$ & 3.88 & 0.96 & 4 \\
\hline
\end{tabular}




\begin{tabular}{|c|c|c|c|c|}
\hline No & Paragraph & Weighted average & Standard deviation & Rank \\
\hline 5 & $\begin{array}{l}\text { financial data through the electronic computer tools } \\
\text { The external auditor shall review the means of auditing using the computer in a } \\
\text { manner that ensures that the computers can properly perform the accounting and } \\
\text { auditing functions }\end{array}$ & 4.25 & 0.76 & 2 \\
\hline 6 & $\begin{array}{l}\text { The auditor verifies the legal degree of the ability of the computer software and its } \\
\text { components to absorb the functions of accounting and auditing in banks and that it } \\
\text { is understood according to the language of the computer }\end{array}$ & 4.26 & 0.78 & 1 \\
\hline 7 & $\begin{array}{l}\text { The external auditor shall counted internal control procedures, accounting } \\
\text { information and procedural functions within the organizational computer unit }\end{array}$ & 3.70 & 1.00 & 6 \\
\hline \multicolumn{2}{|c|}{ Weighted average } & 3.93 & 0.65 & \\
\hline
\end{tabular}

Note from Table 2 that the sample of the study confirms that the sixth paragraph has the highest average of 4.26 which is high value, indicating that the ratios of the strongly approved, and this paragraph is that computers help the auditor To ensure that the accounting data has been processed legally and converted into a language understood by the computer. This means that the computer aids the auditor in ascertaining the existence of the legal authorization to use the accounting data, which leads the auditor to understand general concepts in the And this helps to increase the efficiency of the auditor using computers as a tool of important auditing tools, especially at the present time in which the electronic work environment is dominant in the work environment in different types of enterprises, also notes that the fifth paragraph represents the second degree of acceptance An average of 4.25. This paragraph is that the computer technology allowed the auditor to test the procedures of control and security of information on computers, which helped the auditor to link the audit process to the electronic control system, which reflected positively on the existence of a qualitative leap in nature Which requires the auditor to develop audit procedures so that he can keep abreast of the technological developments in the electronic work environment. It is also noted that the standard deviation of this paragraph is 0.76 , which indicates that the rate Disagreement in respondents' responses to the sample of the study is good. It is also noted that the third paragraph represents the lowest degree of acceptance or confirmation of the sample of the study sample with an average of 3.50. This paragraph is the definition of what allows auditors to exit the work (such as reading, Programs) at specific times and with the allocation of specific programs and data for each terminal end of this means that the work of the auditor has become specific with the presence of certain powers of the auditor in the computerized accounting software It is also noted that the average hypothesis is 3.93 , which is higher than the average satisfactory 3 , this indicates that the sample of the study confirms that the computer had a positive impact in the development of the work of external auditing in the State of Kuwait also notes the ratios of standard deviation close to each other, The dispersion criterion in the responses of the study sample individuals is fairly acceptable compared to the averages obtained.

The second hypothesis that "there is no role for the software auditing technology in the development of the performance of the external audit of audit offices in jordan.

Table 3. The views of the study sample by the variable of the managerial control.

\begin{tabular}{|c|c|c|c|c|}
\hline No & Paragraph & Weighted average & Standard deviation & Rank \\
\hline 1 & $\begin{array}{l}\text { The external auditor keeps pace with technological developments in the design and } \\
\text { development of external audit programs so as to facilitate the implementation of the } \\
\text { external audit }\end{array}$ & 4.02 & 0.90 & 3 \\
\hline 2 & $\begin{array}{l}\text { Computerized audit programs help the external auditor to audit various types of } \\
\text { businesses }\end{array}$ & 4.22 & 0.92 & 1 \\
\hline 3 & $\begin{array}{l}\text { The electronic audit programs help the external auditor to provide useful information } \\
\text { to stakeholders in the auditing firm }\end{array}$ & 4.07 & 0.89 & 2 \\
\hline 4 & $\begin{array}{l}\text { The audit programs used by external auditors provide more accurate information on } \\
\text { the efficiency of internal controls in the audited companies. }\end{array}$ & 3.74 & 0.92 & 6 \\
\hline 5 & $\begin{array}{l}\text { Audit programs used by auditors help to provide a forecast of the financial position } \\
\text { and control of firms under audit }\end{array}$ & 3.89 & 0.92 & 4 \\
\hline 6 & $\begin{array}{l}\text { The audit programs used by the external auditors are characterized by providing clear } \\
\text { information in an accessible language, whether to the management or the board of } \\
\text { directors of the audited companies }\end{array}$ & 3.63 & 0.88 & 7 \\
\hline 7 & $\begin{array}{l}\text { Audit programs use computers and other advanced means to process, obtain, process, } \\
\text { store, and retrieve data obtained (this is right) }\end{array}$ & 3.81 & 0.81 & 5 \\
\hline \multicolumn{2}{|c|}{ Weighted average } & 3.91 & 0.53 & \\
\hline
\end{tabular}

It is noted from Table 3 that the sample of the study confirms that the second paragraph is the most applied paragraphs with an average of 4.22 and a standard deviation of 0.92 . This indicates the strongly approved and approved ratios that are significantly higher than the ratios that are not approved or not strongly approved. On the provisions of the accounting control of electronic processors regardless of the type of industry, and this indicates that the auditor has become an evolution in the work environment on various types of industries in the electronic work environment, which helped to develop external auditing to be able to conduct various types of control to ensure reliability and Accuracy 
and accuracy of accounting data and safety. It is also noted that the third paragraph represents the degree of acceptance or confirmation of the sample of the study sample with an average of 4.07 , namely that the audit programs have the ability to provide the data and information needed for the decision maker to make the decisions that he wishes. This helped the auditor to make the audit process more comprehensive For the needs of users, which helps the auditor to give a more comprehensive picture of the financial position of the company, also notes that the sixth paragraph represents the lowest acceptance of an average of 3.63 and a standard deviation of 0.88 This paragraph is that the audit programs are defined in a language of special understanding, including Of the terms and underlying assumptions and principles that would limit the ability to understand by nonspecialists in accounting This shows the difficulty to take advantage of accounting information even if breached, which helps the auditor to increase the electronic security means data and accounting records. It is also noted that the standard deviation ratios are close to each other, indicating that the dispersion criterion in the responses of the sample members is fairly acceptable compared with the averages obtained.

\subsection{Test the Normal Distribution of Data}

Most of the tests require that the data follow the normal distribution. To verify, the one-sample Kolmogorov-Smirnov Test is done to determine whether the data follows a natural distribution.) At a significance level greater than (0.05), with a value of $Z 0.749$ and a statistical significance of 0.416 . It is clear that the value of $Z$ for all fields of study has a significance level greater than the statistical significance level $(\alpha>$.05).

\section{Conclusions and Recommendations}

\subsection{Conclusions}

1. The presence of computer technology and tools helps the external auditor to reasonably confirm that the data received for processing purposes is licensed and has been properly translated into computer language. This has helped to introduce new functions to the auditor by identifying computer tools, identifying their risks and identifying how to use the computer To achieve external audit objectives.

2. The computer hardware technology helps the external auditor to test the means of control over the electronic system as well as to test the possibility of software in the processing of ordinary accounting data. This helped the external auditor to the possibility of the correct representation of the data of the financial statements through the ability to test the means of computer control, To ensure the existence of security policies for financial statements.

3. The separation of the conflicting functions between the computer department and the external audit helps determine the duties within the computer department and the work of the external auditors. This helped the internal auditor understand the relationship between the computer department and the internal audit work, which makes it easier for the external auditor to perform analytical procedures and comparisons to determine the fairness and validity of the lists. Financial customers.

4. The auditor verifies that the data is complete and correctly entered on the computers and did not result in false information. The reports that have been implemented are properly executed. This helped the auditor to ease the integration of the accounting and financial data from more than one party. Existence of additional value on the validity and credibility of the financial statement data.

5. The programs that are designed to enable the external auditor to review different types of electronic processing systems regardless of the type of organization or industry, and this has helped to develop the competencies of the external auditor through the design of general programs suitable for the financial operations of different types of transactions, which leads to the development of skills Of the External Auditor.

6. Audit programs have the ability to meet the needs of decision makers of the latest information and be linked to the internal control system, and this helps stakeholders to have credibility in the financial statements so that the financial statements were prepared by the computer department and the internal control system and internal audit with the credibility of The external auditor facilitates decision making by stakeholders and increases their confidence in external audit offices in Jordan.

7. The external auditor reviews the electronic systems through the electronic audit programs. These programs are designed to carry out the external audit. This helps the external auditor to review the financial statement data through auditing programs from outside the audited entity, which has a positive impact on the development of the efficiency of external auditors. In the electronic work environment.

\subsection{Recommendations}

Based on the results of the study, the following recommendations can be made

1. There should be legislations and laws governing the work of external auditors in the establishments that use the computer. This should be done through the existence of legislation from the auditors' association that suits the establishments that use the electronic work environment.

2. The need to keep up with the external auditor of Jordan for the latest audits through the development of skills and abilities in the field of electronic work environment, through the specialized accounting courses internal audit and external audit and how to 
coordinate the work between them in the electronic work environment.

3. To hold scientific courses and seminars in the Association of Auditors in Jordan to acquaint external auditors with the latest international auditing standards related to the computer environment and its amendments, in addition to the need to take feedback from external auditors in identifying problems facing external auditors and trying to find appropriate solutions In the electronic work environment.

4. The application of the study to the internal auditors or financial managers and sectors, which helps to integrate the views in the audit process, and this helps to determine the coordination and relationship between the internal auditor and the external auditor in determining the degree of validity and fairness of financial statements.

5. The need for companies specialized in the design and sale of specialized audit programs by industry type and keep pace with the requirements of modern technology.

\section{References}

[1] Dehani, Saud (2017) "Effect of Electronic Auditing in Auditing in Kuwait", Master Thesis, Al Byte University, Mafraq, Jordan.

[2] Ali Ali Al-Ansi1, Noor Azizi Bin Ismail1, \& Abdullah Kaid Al-Swidi (2013) "The Effect of IT knowledge and IT Training on the IT Utilization among External Auditors: Evidence from Yemen, Asian Social Science; Vol. 9, No. 10.

[3] Mohammed AL-Sharairi1, Atallah Al-Hosban2 \&Hussam Thnaibat2 (2018)" The impact of the Risks of the Input of Accounting Information Systems on Managerial Control, Accounting Control and Internal Control in Commercial Banks in Jordan, International Journal of Business and Management; Vol. 13, No. 2.

[4] Juma, Ahmad (2011) "Introduction to Auditing," Dar Wael Publishing, Amman, Jordan.
[5] IFAC, IAAASB (2010) "Hand book international auditing dtandards, IFAC, newyork, USA.

[6] IFAC (2007), ITC, Annual Report IFAC Global Gate away Enoch OK.) 2013. (Lean Accounting and Lean business philosophy in Nigeria: An exploratory research. International Journal of Economics, Finance and Management.

[7] Zu'abi, Abdullah Mohammed and Sulayem, Muhammad Majid, (2013), Building an Integrated Model for the Requirements of Internal Audit in the Accounting Information System and its Impact on the Quality of Accounting Information, Scientific Study presented to the Second International Scientific Conference of the College of Finance and Business. Business Organizations, held during the period 21-22 / 5/2013 at the University of Islamic Sciences, Amman, JordanLopes RB, Freitas F, Sousa. (2015). Application of Lean manufacturing tools in the food and beverage industries. Journal of Technology Management and Innovation and Innovation. 10 (3).

[8] Al-Hosban, Atallah Ahmed (2009) "Internal Audit and Control in the IT Environment" Dar Al-Hamed Publishing, Amman, Jordan.

[9] IIA, (2002) "Current Impact Of Information Technology On Internal Auditing", itaudit, www.iia.org.

[10] Grand, Charles, (2004) "Information Technology In Auditing", itaudit, www.iia.org.

[11] Lotfi, Amin El Sayed (2005) "Audit and Audit of Information Systems, Technical Institute for Printing, Cairo, Egypt.

[12] Arenns, A (2008) Auditing and assurance service, 13RD Edition, Prentice hall, USA.

[13] Al-Thunibat, Ali (2006) Auditing in the light of International Auditing Standards and Local Laws and Regulations: Theory and Application, Dar Wael Publishing, Amman Jordan.

[14] Bany Ahmad, Ahmad (2016) "Compliance of the Audit Offices in Jordan with the Requirements of International Auditing Standard (401)" Auditing in an Information Systems Environment Using a Computer, Master Thesis, Irbid National University, Irbid, Jordan. 